\title{
Unusual Behavior in Grenada Bank Treeboas (Corallus grenadensis)
}

\author{
Craig S. Berg ${ }^{1}$, Billie Harrison ${ }^{1}$, and Robert W. Henderson ${ }^{2}$ \\ ${ }^{1}$ Milwaukee County Zoo, Milwaukee, Wisconsin 53226, USA \\ ${ }^{2}$ Milwaukee Public Museum, Milwaukee, Wisconsin 53233, USA (rh@mpm.edu)
}

$T^{h}$

The Grenada Bank Treeboa (Corallus grenadensis) is endemic to the Grenada Bank, where it occurs on Grenada and on at least ten of the Grenadine Islands. Over the course of many years and hundreds of hours in C. grenadensis habitat, we have been privy to various aspects of its natural history (summarized in Henderson, 2002 and 2015). Although we have gleaned a great deal of information about this interesting snake, each visit into C. grenadensis habitat has the potential for surprises, raising — and sometimes answering - new questions.

Fieldwork on Grenada and Carriacou during March 2015 provided photographic documentation of: (1) Activity that had been described by local residents but which we had never seen, (2) foraging behavior that we did not understand, and (3) foraging behavior in proximity to a very large prey item.

Use of electrical transmission lines.-Snakes, most notoriously Brown Treesnakes (Fritts et al. 1987; Fritts and Chiszar 2009), are known to occasionally use utility lines to bridge gaps between arboreal vegetation. We had heard stories of C. grenadensis using utility lines to cross from one side of a street to the other in Birch Grove (St. Andrew Parish). Birch Grove is centrally located in Grenada, and on the main road that connects the country's two largest towns (St. George's and Grenville). Because of its location it receives considerable vehicular traffic within the town limits, but also on its outskirts, where treeboas would be more apt to occur (although we do not doubt their presence in the town proper). Boas

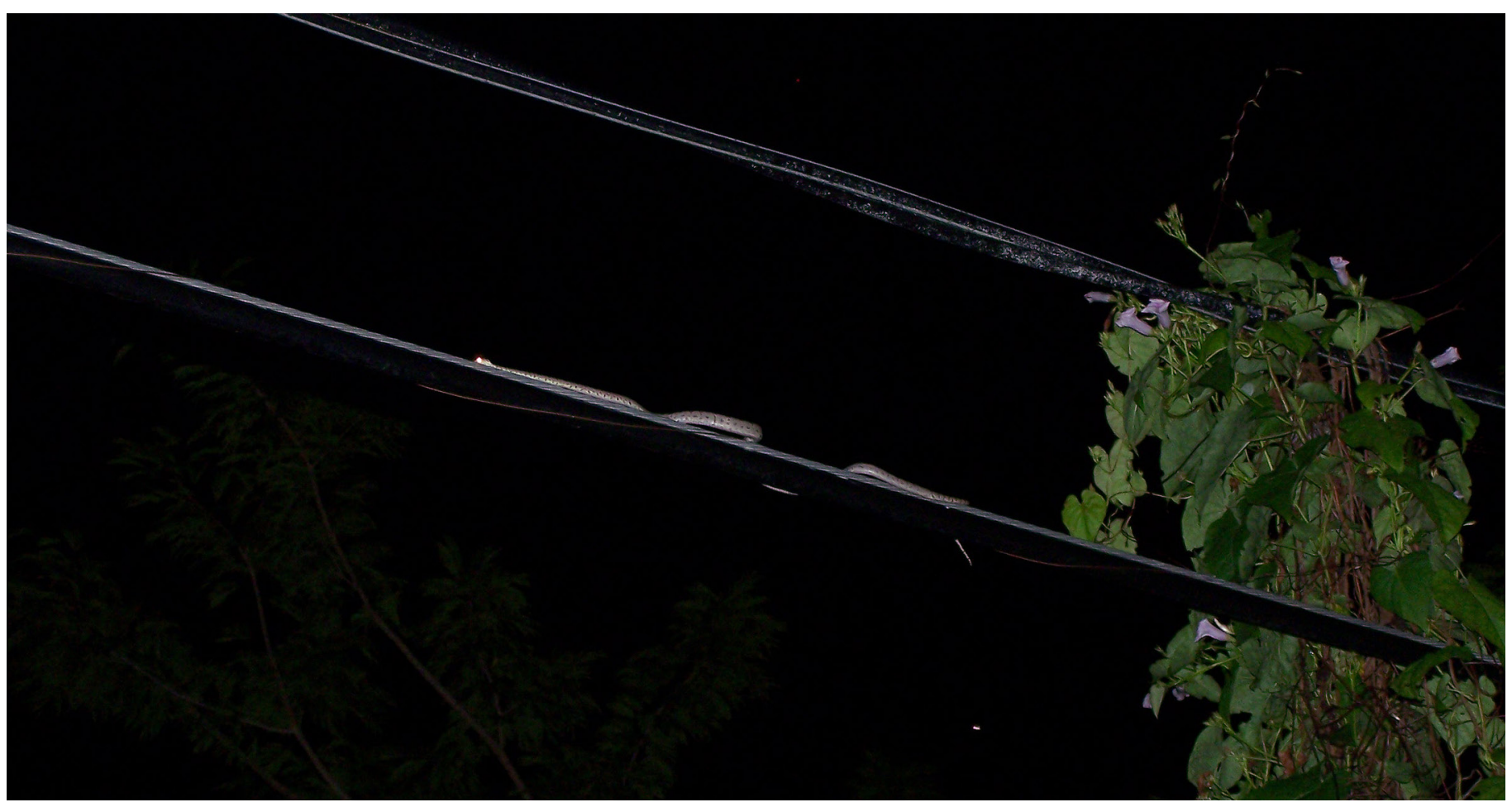

Fig. 1. A yearling Grenada Bank Treeboa (Corallus grenadensis) using an electrical transmission line to bridge a gap between arboreal vegetation. Note the reflective eye-shine that facilitates the observation of these nocturnal snakes. Photograph by Craig. S. Berg.

Copyright (C) 2015. Craig S. Berg. All rights reserved. 


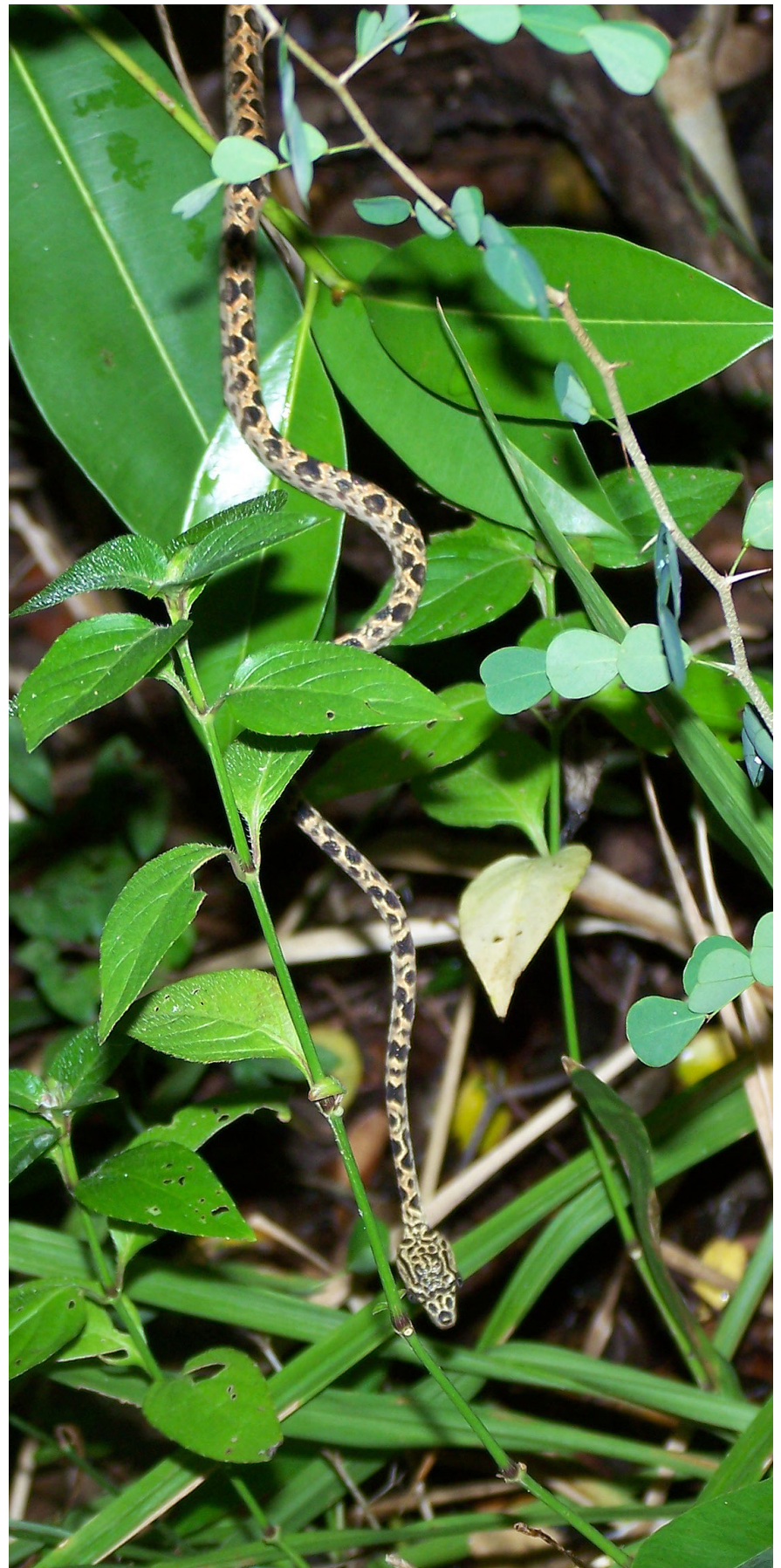

Fig. 2. A young-of-the-year Grenada Bank Treeboa (Corallus grenadensis) in a typical ambush posture. Photograph by Craig. S. Berg.

were known to occasionally get electrocuted on their crossing. These observations were voluntarily offered to us, and we have never doubted their accuracy.

At Westerhall Estate (St. David Parish) on 20 March at 1900 h, we observed a yearling C. grenadensis using a power line to bridge a gap between arboreal vegetation (Fig. 1). The lines paralleled the dirt track on which we were walking. We have been working at Westerhall for more than 20 years, and this is the first time we have witnessed this mode of gap-bridging.
Ambush foraging?-Neonate to subadult Corallus grenadensis are active foragers that prey frequently on Anolis lizards and occasionally on Iguana iguana (Henderson 2015; Henderson and Pauers 2012). On 26 March at Westerhall, CSB observed a young-of-the-year C. grenadensis in an ambush posture typical of adults. Adult $C$. grenadensis will suspend from a branch with the head angled toward the ground and often within $15-30 \mathrm{~cm}$ as they await a passing rodent or marsupial. The young snake observed at Westerhall had its head angled downward and about $5-7 \mathrm{~cm}$ above the ground (Fig. 2). We cannot imagine what it was expecting to capture. Anolis lizards would be sleeping on vegetation much higher above the ground and could only be encountered by active foraging. Although the introduced frog Eleutherodactylus johnstonei is occasionally taken by small treeboas (Rush et al. 2013), those frogs also are more or less stationary when active. The boa was much too small to capture, subdue, and ingest an active rodent, so what was it doing?

This episode was reminiscent of an observation made at a site in central Grenada on 29 October 2013. A subadult $C$. grenadensis was observed from $2045 \mathrm{~h}$ to $2150 \mathrm{~h}$. During that time it faced a tree trunk from a distance of about $25.0 \mathrm{~cm}$ (Fig. 3). It was not going to encounter an anole, and it seemed unlikely that a small rodent would ascend the tree trunk near that precise spot. Geckoes (Hemidactylus and Thecadactylus) would be the most likely prey encountered in that situation, but geckoes have not so far been documented in the diet of C. grenadensis.

Foraging near a large lizard.-As noted, young treeboas feed almost exclusively on sleeping lizards. On 23 March at a site on Carriacou, CSB watched as a yearling C. grenadensis

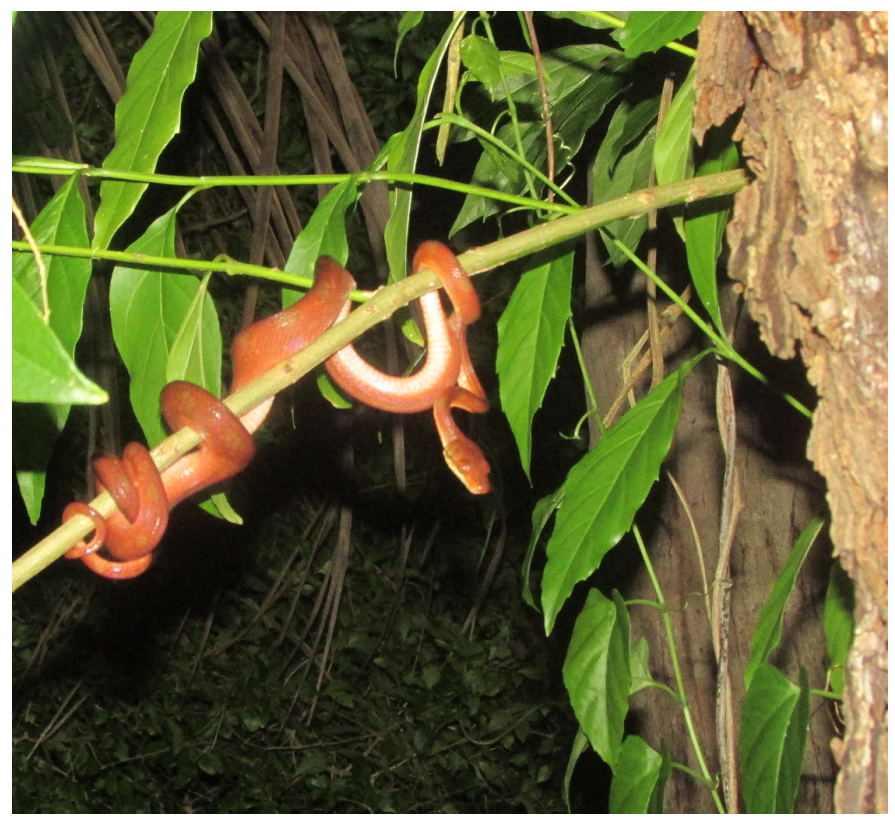

Fig. 3. A subadult Grenada Bank Treeboa (Corallus grenadensis), presumably in an ambush foraging posture. Photograph by Robert W. Henderson. 


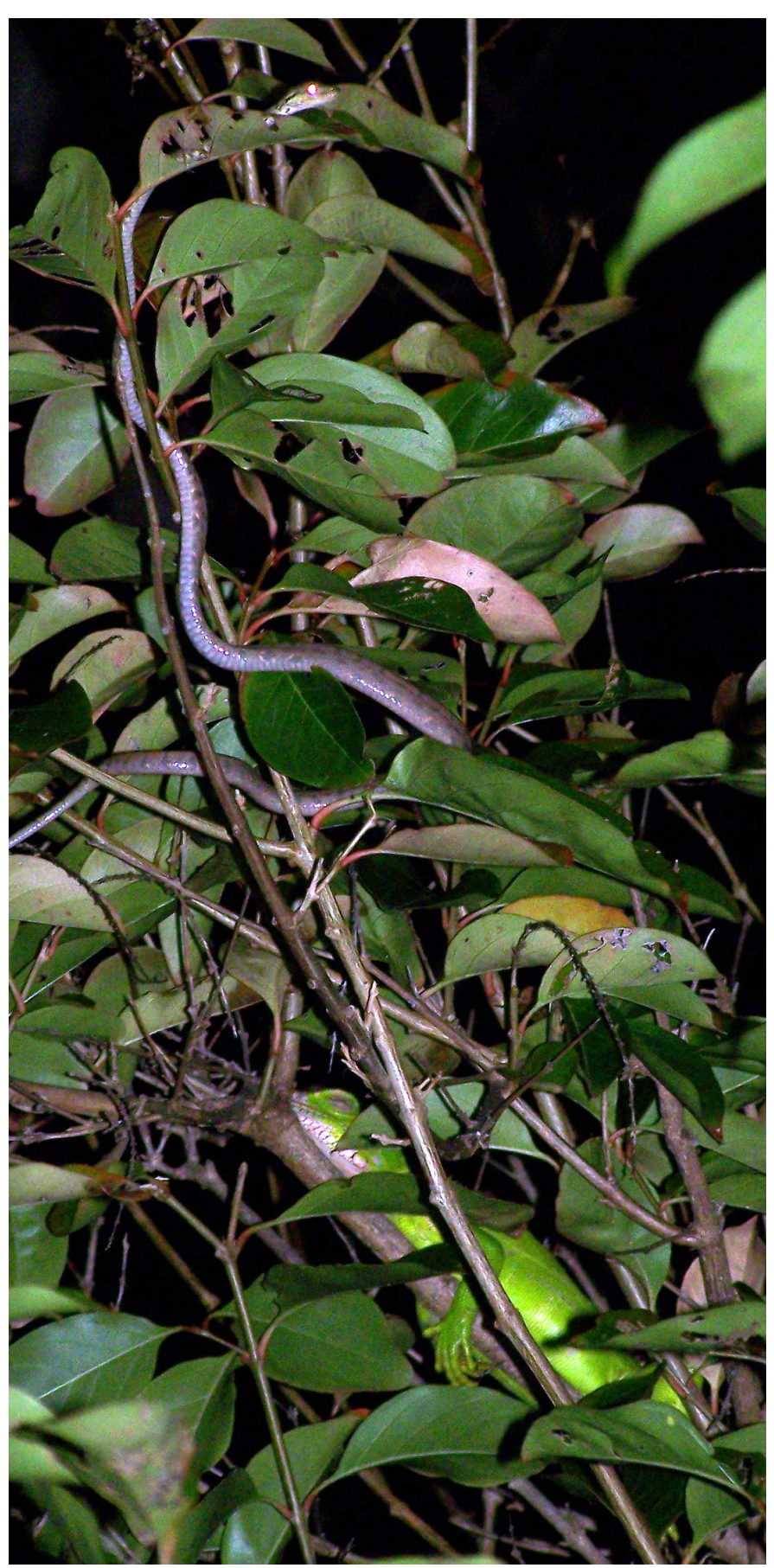

Fig. 4. A yearling Grenada Bank Treeboa (Corallus grenadensis) actively foraging in proximity of a sleeping Green Iguana (Iguana iguana). As in Fig. 1, note the distinctive eye-shine. Photograph by Craig. S. Berg. moved around a sleeping Green Iguana (Iguana iguana; Fig. 4). For about 15 minutes, the boa appeared to be foraging and was at times within $5-30 \mathrm{~cm}$ of the iguana. At no time while being observed did it appear to direct its attention specifically to the iguana, perhaps realizing it was too large to be potential prey. Yorks et al. (2003) described a similar situation in which a foraging C. grenadensis and an adult Thecadactylus rapicauda crossed paths, but the boa showed no overt interest in the gecko.

\section{Literature Cited}

Fritts, T.H. and D. Chiszar. 1999. Snakes on electrical transmission lines: Patterns, causes, and strategies for reducing electrical outages due to snakes, pp. 89-103. In: G.H. Rodda, Y. Sawai, D. Chiszar, and H. Tanaka (eds.), Problem Snake Management: The Habu and the Brown Treesnake. Cornell University Press, Ithaca, New York.

Fritts, T.H., N.J. Scott, and J.A. Savidge. 1987. Activity of the arboreal Brown Tree Snake (Boiga irregularis) on Guam as determined by electrical power outages. Snake 19:51-58.

Henderson, R.W. 2002. Neotropical Treeboas: Natural History of the Corallus hortulanus Complex. Krieger Publishing Co., Malabar, Florida.

Henderson, R.W. 2015. Natural History of Neotropical Treeboas (Genus Corallus). Edition Chimaira, Frankfurt am Main, Germany.

Henderson, R.W. and M.J. Pauers. 2012. On the diets of Neotropical treeboas (Squamata: Boidae: Corallus). South American Journal of Herpetology 7:172180.

Rush, E.M., R.W. Henderson, M. Drake, and N.M. Lonce. 2013. Predation on the introduced frog Eleutherodactylus johnstonei by the arboreal boid Corallus grenadensis. Herpetology Notes 6:353.

Yorks D.T., K.E. Williamson, R.W. Henderson, R. Powell, and J.S. Parmerlee, Jr. 2003. Foraging behavior in the arboreal boid Corallus grenadensis. Studies on the Neotropical Fauna \& Environment 38:167-172. 